\title{
POLÍTICAS EDUCACIONAIS E PEDAGOGIA DA EXCLUSÃO: A ESCOLA EM XEQUE NO BRASIL DO SÉCULO XXI
}

\section{Educational politicas and pedagogia of de Exclusion: the school in Brazil of the century XXI}

Maria de Lourdes Pinto de Almeida ${ }^{1}$

\section{Resumo}

Neste trabalho, pretendo abordar criticamente algumas dimensões da configuração das políticas educacionais no discurso neoliberal do campo educacional, tendo como foco de análise a Escola. Começarei destacando a importância teórica e política de se compreender o neoliberalismo como um complexo processo de construção hegemônica das relações sociais e educacionais vigentes no terceiro milênio, ou seja, como uma estratégia de poder que se programa em sentidos articulados: por um lado, por meio de um conjunto razoavelmente regular de reformas concretas no plano econômico, político, educacional e, por outro, mediante uma série de estratégias orientadas a impor novos diagnósticos acerca da crise e construir novos significados sociais a partir dos quais visa a legitimar as reformas neoliberais como sendo as únicas que podem (e devem) ser aplicadas no atual contexto histórico de nossa sociedade civil. Tentarei mostrar de que forma esta dimensão educacional, característica de toda lógica hegemônica, foi sempre reconhecida como um importante espaço de construção política por aqueles intelectuais conservadores que, em meados deste século, começaram a traçar as bases teóricas do neoliberalismo enquanto alternativa de poder na práxis pedagógica. Na seqüência, tentarei apresentar algumas considerações gerais sobre como se constrói a retórica neoliberal no campo educacional. Meu objetivo será questionar a forma neoliberal de pensar e projetar a política educacional. Finalizo destacando algumas das mais evidentes conseqüências da pedagogia da exclusão promovida pelos discursos educacionais em prol da construção de uma cidadania outorgada!

Palavras-chave: Pedagogia da Exclusão; Política Educacional; História da Educação e da Escola.

1 Doutora em Educação, Professora da Universidade de Campinas e da Pontifícia Universidade Católica de Campinas. Correio Eletrônico: malu04@uol.com.br 


\section{Abstract}

I intend to approach some dimensions of the configuration of the educational politics in the neoliberal speech of the educational field having as focus of analyzes the School. I will start detaching the theoretical importance and politics of if understanding the liberalism as a complex process of hegemonic construction of effective the social and educational relationsin third millennium., or either, as a strategy of being able that program in articulated directions: on the other hand, by means of a set to regulate of concrete reforms in the economic plan, politician, educational e, for or through a series of guided strategies imposing new diagnostic concerning the crisis and constructing new social meanings from which aims at to legitimize the liberal reforms as being the only ones that they can (and they must) be applied in the current historical context of our civil society. I will try to show of that it forms this educational dimension, characteristic of all hegemonic logic, was always recognized as an important space of construction politics for those intellectual conservatives who, in middle of this century, had started to trace the theoretical bases of the liberalism while alternative of being able in the praxis pedagogical. In the sequence, I will try to present some general points on as if it constructs the liberal rhetoric in the educational field. My objective will be to question the liberal form to think and to project the educational politics. I finish detaching some of the consequences of the pedagogy of the exclusion promoted for the educational speeches in favor of the construction of a granted citizenship!

Keywords: Pedagogy of the Exclusion; Educational politics; History of the Education and the School.

\section{Introdução}

(...) não parte dos fatos, mas dos materiais históricos, das fontes, no sentido mais extenso deste termo, com a ajuda dos quais constrói o que chamamos de fatos históricos. Constrói-as na medida em que seleciona os materiais disponíveis em função de certo critério de valor, como na medida em que os articula, conferindo-lhes a forma de acontecimentos histónicos. Assim, a despeito das aparências e das convicções correntes, os fatos históricos não são um ponto de partida, mas um resultado (SHAFF, 1987, p. 307).

Neste início de século XXI, podemos afirmar com conviç̧ão que sabemos muito mais sobre a natureza e os limites da administração pública, em termos gerais e no Brasil em particular, assim como sobre suas relações complexas com o sistema político e a cultura do país, do que na História da Educação dos séculos anteriores. O resultado desta maior sabedoria, no entanto, não tem sido melhorar a capacidade governamental em formular políticas e levá-las a cabo, mas um grande ceticismo a respeito do que se possa ser 
feito; ceticismo reforçado pelas experiências frustrantes das gestões pós Ditadura Militar, mais precisamente, pós 1984.

A história, enquanto ciência, mostra como um produto de seu tempo, das forças sociais que disputam a hegemonia. Basta ver como a concepção de história de Santo Agostinho é filha de seu tempo. Ali tudo parece se coadunar com o domínio católico e com a manutenção das novas relações de produção feudal. Os males da cidade dos homens só seriam suprimidos frente ao advento da cidade de Deus, da qual a Igreja seria a porta voz. Do mesmo modo, pode se falar de Voltaire. Esse "iluminista" procura fundamentar a história de modo a fazer dela uma ciência em consonância com os novos tempos, ou seja, com a emancipação da burguesia. Como vimos, o próprio materialismo histórico é um saber ligado às condições materiais de seu tempo, tanto no que concerne à metodologia quanto em suas concepções gnosiológicas e ontológicas. O mesmo juízo se aplica aos historiadores pós-modernos.

\section{Políticas educacionais e pedagogia da exclusão na escola pública brasileira}

O que temos é que a ciência, enquanto atividade humana, não pode renegar seu caráter histórico de práxis libertadora ou de alienação utilitária, em que estaria a serviço da acumulação do capital. A idéia de "ciência una" nos possibilita pensar as atividades científicas das mais diversas 'especialidades' como um fazer integrado historicamente, quer para maximizar os lucros do capital ou quer para contribuir no sentido de liberar o "gênero humano", que nas condições atuais do capitalismo significaria contribuir no sentido da luta pela emancipação da classe trabalhadora. Portanto, nenhum saber é neutro, mesmo quando sua aplicação restringe o mais ínfimo dos aperfeiçoamentos de uma máquina. Tanto o saber quanto a máquina estão inseridos em um contexto cuja compreensão nos revelaria as suas implicações históricas. Nesse sentido, as informações precisas e atualizadas são fundamentais para a acumulação do capital. O saber é uma mercadoria. Como diz Harvey (1992, p. 151), "o acesso à informação" tornou-se fundamental para garantir lucros:

O acesso à informação, bem como o seu controle, aliados a uma forte capacidade de análise instantânea de dados, tornaram-se essenciais à coordenação centralizada de interesses corporativos descentralizados. A capacidade de resposta instantânea a variações das taxas de câmbio, mudanças das modas e dos gostos e iniciativas dos competidores têm hoje um caráter mais crucial para a sobrevivência corporativa do que teve sobre 0 fordismo. A ênfase na informação também gerou um amplo conjunto de consulto rias e serviços altamente especializados capazes de fornecerinforma- 
ções quase minuto a minuto sobre tendências de mercado e o tipo de análise instantânea de dados útil para as decisões corporativas. (...). O acesso ao conhecimento científico e técnico sempre teve importância na luta competitiva; mas, também aqui, podemos ver uma renovação de interesse e de ênfase, já que, num mundo de rápidas mudanças de gostos e necessidades e de sistemas de produção flexíveis (em oposição ao mundo relativamente estável do fordismo padronizado), o conhecimento da última técnica, do mais novo produto, da mais recente descoberta científica, implica a possibilidade de alcançaruma importante vantagem competitiva. O próprio saber se toma uma mercadoria-chave, a ser produzida e vendida a quem pagarmais, sob condições que são elas mesmas cada vez mais organizadas em bases competitivas. Universidade e institutos de pesquisa competem ferozmente por pessoal, bem como pela honra de patentear primeiras novas descobertas científicas (...). A produção organizada do conhecimento passou pornotável expansão nas últimas décadas, ao mesmo tempo em que assumiu cada vez mais um cunho comercial (como o provam as incômodas transições de muitos sistemas universitánios do mundo capitalista avançado de guardiões do conhecimento e da sabedoria para produtores subordinados de conhecimento a soldo do capital corporativo).

O acesso ao conhecimento científico e técnico é fundamental na luta competitiva entre capitalistas, mas ele o é também no sentido da luta de classes. Nesse sentido, a "ciência única" tornar-se-ia a forma básica para se compreender as várias práticas locais - do saber e do fazer - não como singularidades imediatas, mas, sobretudo, como integradas numa concretude histórica, cuja visão de conjunto - "metanarrativa" - nos possibilitaria compreender, de modo crítico, a quem serve determinadas opções metodológicas e, sobretudo, no que se refere à escolha dos objetos - conforme a finalidade de uma produção de um saber local - aplicável, conversível em tecnologia.

Curiosamente, hoje em dia, há certa moda 'ideológica' de que estaríamos nos tempos dos fins: não da história, da ideologia, mas do "trabalho", da "ciência", da "guerra".

O "mercado" parece ter sido um dos únicos conceitos bem-sucedidos, ou eficientíssimo, pois ninguém parece ter coragem de sepultá-lo ou mesmo de antever a possibilidade de sua morte. Com o acirramento da concentração de rendas e as novas formas de exploração, que mais do que nunca contam com a exclusão social e todas as "novas" formas de perversidades sociais - guetos, violência entre gangues, máfias e todo o circuito perverso da "economia informal" etc., e, sobretudo, com os retrocessos em termos de direitos trabalhistas, dizer que o "marxismo", não só como instrumento metodológico, mas ideológico, no sentido de utopia-programa, soa como dizer que a filosofia morreu, e como teria dito Deleuze a respeito deste óbito, poderíamos dizer também que se o marxismo "morreu", ou está "agonizando", deve morrer, com certeza de tanto rir. 
Até uns anos atrás tínhamos a morte do marxismo como tragédia, agora, sem dúvida, devemos vivê-la como farsa, ou melhor, comédia. Para falamos com "rancor", o que significa ideologicamente, mas não "ressentidamente", os piores mortos são aquelas vítimas da fúria local e global do capital. Enquanto o número deles estiver aumentando ou, mesmo existindo, acredito que a ciência, ou deve estar do lado dos "vivos", ou dos vitalizados pelo capital ou deve estar do lado dos mortos, ou melhor, daqueles que estão sendo mortos não tanto pelas armas ideológicas, mas, sobretudo, pela perversidade inerente à exploração capitalista.

Neste contexto histórico atual, se faz mister afirmar que há uma necessidade de ficarmos atentos a um dos efeitos ardilosos da crise generalizada que atingiu as ciências humanas no final da década de 90 e virada de novo milênio, que foi o de trazer o fenômeno caracterizado como a 'a volta do sujeito', implícitos neste fenômeno aparentemente normal e sem maiores implicações existem equívocos que podem representar uma total desorientação teórica e metodológica. Esta volta do sujeito pode levar desde a consideração dos sujeitos enquanto sujeitos históricos da ação coletiva, até a subjetivação do sujeito, ou a o retorno do personagem da história narrativa ou dos protagonistas individuais da história oficial do ator, tendo a história como simples cenário.

Frente a estas transformações econômicas das últimas décadas, a Escola Pública sofreu os impactos da globalização. O enfraquecimento do Estado, principalmente com a crise fiscal e o prevalecimento de políticas de redução da ação e do investimento do governo no setor social, especialmente na Educação Escolar, a Instituição Educacional Brasileira sofreu com a redução dos investimentos resultantes de uma política asfixiante para o setor.

O indivíduo necessita continuamente adquirir os atributos necessários para concorrer a um lugar no mercado. Neste contexto, o fato de o indivíduo não conseguir emprego não é atribuído à falta de oportunidades, mas porque ele não preenche os requisitos necessários para isso, cabendo a ele, portanto, buscar suprir de forma contínua esses itens para que ele possa ser "empregável". O indivíduo necessita continuamente adquirir os atributos necessários para concorrer a um lugar no mercado.

Isso devido ao fato de que a Escola perde cada vez mais a sua antiga função intelectual-cultural-social, para assumir um caráter mais social. A Escola acaba por ser cooptada nessa rede pelo setor econômico. O indivíduo, livre das amarras da Escola e do sistema de ensino, torna-se o único responsável pelo seu êxito ou fracasso. Por isso, ele precisa de forma permanente estar se qualificando e adquirindo competências e habilidades flexíveis para responder adequadamente às demandas aceleradas postas pela atual forma de acumulação do capital. 
Umas das conseqüências mais drásticas desse processo é o aumento do fosso entre ricos e pobres. Ao entrar no jogo da globalização, a Escola tende a perder suas raízes, sua nacionalidade e a distanciar-se cada vez mais dos interesses locais e da comunidade no interior da qual teve sua origem e para a qual foi originariamente pensada.

Assim, a Escola que traz um "ensino" globalizado tende a favorecer aqueles que comandam o processo de globalização do capital. Isso se verifica no aprofundamento da exclusão dos países pobres que perderam um espaço para lutarem contra a miséria na qual está imersa a maioria de suas populações.

Com a globalização e a privatização do sistema escolar, o conhecimento tende a ser uma mera mercadoria e a ciência perde o seu caráter de bem comum. O processo de globalização das Instituições Escolares, no qual a América Latina está se aprofundando, as chances de uma afirmação econômica dos países da região tendem a ser cada vez menores, o que acentuará mais o processo de dependência e exclusão, uma vez que se perde paulatinamente a capacidade de autodeterminação.

Nesse sentido, observa-se um deslocamento do eixo "ensinar para o aprender" e do "formar para o treinar", caracterizando um novo tecnicismo, com um tipo de ensino centrado no estudantes e nas redes de educação por onde ele pode navegar e acessar a qualquer momento o estoque de informações disponíveis de modo "democrático' e, com isso, compor sua "cesta básica" de informações e de conhecimentos.

Este novo tecnicismo, chamado de "novo paradigma" do conhecimento, leva à centralidade da educação e do trabalho nas orientações das políticas de intervenção deliberadas, postas em prática por organismos multilaterais como Banco Mundial; Comissão Econômica para a América Latina e Caribe - CEPAL; Organização das Nações Unidas para Educação, Ciência e Cultura - UNESCO; Banco Interamericano de Desenvolvimento - BID e pelo Estado Brasileiro (pólo de Consentimento), na medida em que revinculam o desenvolvimento humano de forma mecânica a uma educação aligeirada e a um trabalho precarizado, reeditando a teoria do capital humano.

Ainda que historicamente cada região trilhasse um caminho próprio, as nações tendem a homogeneizar os programas de Escolarização diante das propostas e investidas do Banco Mundial, o que torna os países desenvolvidos e dominantes mais integrados. A este respeito, diz Castells (1999, p.125): "se tomarmos interdependência financeira, transferência de tecnologia, interligações e joint ventures entre empresas, fica claro que o núcleo da economia global é uma rede extremamente interdependente entre EUA, Japão e Europa Ocidental". Trata-se do poder da tríade. Assim, a globalização intensifica as inter-relações nacionais não só em matéria de comércio, finanças e produção, 
mas também de inovação tecnológica e investigação científica. Contudo, essa tendência à homogeneização, que leva até mesmo os países europeus a repensarem o papel da Educação frente ao mercado, se dá a partir de uma base histórica já constituída que marca cada nação ou mesmo região.

Para os países que não controlam os fluxos da globalização, essa tendência acentua ainda mais a dependência econômica, sem falar no processo de desmonte de sistemas Educacionais, em que o aluno procura a Escola para lazer, romance, entretenimento, e quase nunca para aprender o saber sistematizado que irá formar sua consciência política e de classe.

No Brasil, a Educação Pública está sendo desestruturada devido ao corte de investimentos, as privatizações ou desnacionalização, sucateamento das Escolas, que tendem também a ser parcial ou totalmente privatizadas (adotar o regime de cobranças de mensalidades, ou serem mesmo transferidas para a iniciativa privada e ou comunitária).

Neste cenário, destaca-se uma instituição que tem fator determinante nas decisões da política educacional. Trata-se do Banco Mundial, que teve suas atividades iniciadas em 1944, na Conferência de Bretton Woods, vinculado ao Fundo Monetário Internacional e tendo como preocupação central o estabelecimento de uma nova ordem internacional após a Segunda Guerra Mundial.

O tema docente é um dos que passam a incomodar o Banco Mundial. Os professores são vistos como um sindicato magisterial que lembra reivindicação salarial, greve, quando não simples corrupção e manobra política. Uma classe complexa e difícil de lidar.

Mediante programas paliativos, de preferência a distância, o Banco Mundial não considera significativo investir na formação prévia; nesse sentido, o Banco está imprimindo uma direção política e ideológica no que se refere à educação geral e à formação docente em especial, a partir do critério economicista. Vive-se hoje num mundo marcado por crise de valores, crise social, crise moral, em que a sociedade transformou-se em uma sociedade banco de dados, tamanho é o volume de informações que não instrumentam nem ajudam o indivíduo de um modo natural. Educação existe quando há pessoas interessadas. Segundo Dermeval Saviani, na maioria de sua obra, só há educação onde há esperança. E este interesse é transformar um dado em uma informação e informação é diferente de educação, e é menos que conhecimento.

No livro 0 pós moderno, Lyothard, já no final da década de 70 , chamava a atenção para uma tendência segundo a qual o conhecimento teria cada vez mais um caráter estratégico, ou seja, perderia sua aura de público, tendendo a converter-se cada vez mais em mercadoria, em bem privado, escasso, cujo uso por um, priva os outros do bem em questão. Segundo o autor, 
o saber é e será produzido para ser vendido, e ele é e será consumido para ser valorizado numa nova produção: nos dois casos, para ser trocado. Ele deixa de ser para si mesmo seu próprio fim.

Lyothard fala também das mudanças nas bases de legitimação da ciência. O saber tenderia a não se legitimar conforme "a grande metalíngua" nas quais todas as demais podem ser transcritas, mas conforme a eficácia ou desempenho, baseando-se agora no critério da operatividade, que é o tecnológico. Tal critério não diz respeito ao verdadeiro e ao justo, mas ao aumento do poder. A conclusão a que se chega é a de que os setores da Educação, que não podem pleitear sua contribuição, mesmo indireta, à otimização das performances do sistema, são abandonados pelos fluxos de créditos e fadados à obsolência.

Nesse sentido, as ciências humanas tenderiam a ser marginalizadas, no que concerne aos financiamentos em função da sua ineficiência ou não aplicabilidade. Mas há pensadores que acreditam no caráter fundamental das ciências humanas para a emancipação das comunidades oprimidas ou excluídas. Desse modo, as ciências humanas seriam incorporadas nos programas de partidos de esquerda, bem como nos movimentos de organização social e política das comunidades ou da auto-organização social. Dever-se-iam criar mecanismos coletivos para que o saber por elas produzido fosse sendo agenciado coletivamente pelas prefeituras e as associações as mais diversas, ou seja, em vista de servir não de modo centralizado, mas, sobretudo, espraiado.

O conhecimento apresenta-se como uma ferramenta de múltiplos usos políticos. Ele tem tanto o caráter político estratégico ou libertário e o de mercadoria no sentido de se fazer valer os interesses econômicos dos capitalistas. O poder emancipatório, em sua capacidade de incrementar o diálogo e as possibilidades de ação da coletividade, passaria pela idéia de que ao mesmo tempo em que a ciência deve romper com o senso comum no sentido de se desenvolver analítica e formalmente, ela deve retornar ao senso comum enquanto disponibilidade e acessibilidade, ainda que seu registro formal deva ser traduzido para uma linguagem mais funcional.

Mas há quem pense que ao servir aos interesses imediatos dos dominantes, a Educação tenderia a médio ou longo prazo, ou ainda de modo indireto, favorecer a toda comunidade, pois o desenvolvimento social em seus mais variados aspectos passaria pelo incremento das privatizações. Essa visão traz em si o preconceito de que apenas a Escola Privada seria uma instância de auto-organização, capaz de agenciar saber e promover benefícios comuns. Assim, a diferenciação de público e privado seria meramente formal, pois, na prática, o agente do bem público não seria o governo, nem muito menos entidades não lucrativas, quer dizer, auto-organizacionais, cooperativas, nem no sentido puro, nem no misto, ou seja, que combinam benefícios imediatos 
em termos de melhorias do nível de vida dos seus participantes e ainda com fins lucrativos.

Considerando que estamos tratando de modo de produção capitalista, portanto, da sociedade burguesa, a ordem social se define pelo antagonismo entre capital e trabalho representado pelas classes sociais constituídas por esse embate: de um lado as classes dominantes e de outro as classes subalternas.

Se a sociedade capitalista se define pelas contradições que desenvolvem isso significa que a sociedade é dinâmica e inacabada. A sociedade burguesa é, portanto, mais um estágio nesse processo histórico da constituição da sociedade e está sujeita a ser superada.

Esta reflexão nos leva a buscar a dinâmica da sociedade, as leis que permitem o movimento da criação e transformação das relações sociais e verificar de modo que se produzem os intelectuais, suas instituições de trabalho e como se imbricam nessas transformações.

Para Marx, só a luta de classe revela a existência desse movimento. Essa é que permite a mudança das condições materiais, modificando e criando novas relações sociais. 0 processo de luta se dá no âmbito da organização social da produção capitalista, pois é nesse momento que se contrapõem dominantes e dominados.

Do confronto de onde surgem os interesses antagônicos e recíprocos há que se pensar como se dá a produção das relações capitalistas ao mesmo tempo em que se busca sua superação.

As condições materiais mudam a partir da luta de classes que implica na mudança das relações entre os indivíduos e suas posições sociais. Estas se determinam na organização da produção e aquela sofrerá transformações somente na mudança desta última.

A pedagogia que se sedimentou desde a instauração da modernidade tem sido articulada à divisão social e técnica do trabalho, tendo como objetivo primordial distribuir e atender as demandas diferenciadas relativas à formação de trabalhadores, de um lado, e de dirigentes, de outro, estabelecendo os limites de uma educação utilitária, para os primeiros e desinteressada para os segundos.

\section{Considerações Finais}

Para Marx, a possibilidade de mudança de transformação de superestrutura jurídica e política só podem ocorrer de forma real a partir das transformações da base econômica, ou seja, na mudança de posições sociais geradas pelo antagonismo de classes, somente assim a consciência social poderá ser reflexo de uma nova ordem social. 
A reprodução ou transformação da base econômica reproduzirá ou transformará as formas jurídicas, religiosas, artísticas ou filosóficas correspondentes à superestrutura da sociedade. É na organização da produção que se encontram e se dinamizam as relações sociais e os determinantes do poder político e da hierarquia social. Na luta entre a burguesia e o proletariado, os primeiros ao controlar e acumular capital desenvolve a sua imagem, a sociedade civil, condicionado a formação cultural e a moral social. A consciência de ambos é formada pelas relações de produção, condicionando também 0 modo de vida e o desenvolvimento social do indivíduo, ou seja, o pensamento, a formação de ser e agir da classe dominante.

Para Marx e Engels, a sociedade burguesa, além de expropriar dos trabalhadores os meios de produção material, expropria juntamente os meios de produção cultural.

as idéias da classe dominantes são as idéias dominantes em cada época; dito de outra maneira, a classe que exerce o poder material dominante na sociedade é também ao mesmo tempo seu poder espiritual e dominante. A classe que teve a sua disposição os meios para produção material dispõe juntamente e ao mesmo tempo dos meios para a produção espiritual, o que faz com sejam submetida nesse tempo as idéias daqueles que não têm os meios necessários para produzir espiritualmente. As idéias dominantes não são outra coisa que expressão ideal das relações materiais dominantes, as mesmas relações dominantes concebidas como idéias; portanto, as relações que fazem uma determinada classe, a classe dominante, são também as que conferem o papel dominante as suas idéias. Os indivíduos que formam a classe dominante têm também, entre outras coisas, a consciência de sê-la e pensam de acordo com ela; porisso enquanto dominam sua classe, enquanto determinam todo o âmbito de uma época histórica, se compreende que a façam em toda sua extensão e portanto, entre outras coisas, também como pensadores, como produtores de idéia que regulam a produção e a distribuição de idéias de seu tempo; e que suas idéias sejam por isso mesmo as idéias dominantes na época (MARX; ENGELS, 1974. p. 50-51)

A essa afirmação pode se entender que os indivíduos e as instituições políticas, econômicas e culturais na sociedade burguesa são produtos das relações de produção capitalista.

As classes dominantes monopolizam a ciência, a arte e a dimensão mais ampliada da cultura. A ciência passa a ser um instrumento de apropriação cultural e espiritual nas mãos da classe dominante que a usará como meio de extorsão da mais valia.

Há uma divisão entre a base econômica e a superestrutura jurídica, política e ideológica, e quando há base econômica antagônica, pois evidencia a relação capital versus trabalho, ou dominantes e dominados, as esferas que se 
manifestam na superestrutura que apresentam como homogêneas, aparentemente sem contradições de classe. É por isso que Marx e Engels rejeitam as instituições da sociedade burguesa, pois para eles são produção e reprodução da cultura e necessariamente a produção e reprodução da cultura burguesa. Os dominados, sob a orientação dos proletánios, terão que criar consciência de classe e para sua classe no processo de produção, pois é lá que se manifesta a reprodução da vida material. Para isso, a classe proletária deve usar meios políticos para fazer valer as idéias e seus princípios oriundos de sua condição material de vida.

Diante do acima exposto, se faz mister dizer que a sociedade da informação e do conhecimento; sociedade do não emprego e das novas configurações do trabalho, onde o trabalho do professor está sendo terceirizado; crise da modernidade; era da irracionalidade posta neste início de terceiro milênio; a deterioração das condições humanas, da violência, da vida e das relações humanas que se reduzem a contatos fragmentários e temporários, além de utilitaristas, põem a Escola, em uma necessidade histórica urgente de se requalificar. Isto porque, no contexto atual das políticas neoliberais, ela não é viável como projeto pedagógico.

É necessário, então, que a escola seja repensada para que possa transformar a informação em conhecimento socialmente significativo para 0 conjunto da população.

Coerente com esta lógica, as políticas educacionais não teriam mais necessidade de se preocupar com a garantia do acesso de todos à educação; cada um deve buscar este acesso individualmente (e isto já representa um critério de seleção) no mercado. Os "mais aptos" nesta tarefa tenderão a sobreviver e a integrar o fluxo contínuo de progresso.

A educação dentro deste tipo de enfoque está perdendo a perspectiva de ser integradora para aprofundar a sua função de justificadora das desigualdades sociais. A educação deslocou-se, portanto, da esfera do direito social para colocar-se no plano individual, cuja regra central e o critério de mercado.

\section{Referências}

CASTELLS, M. A Sociedade em rede. São Paulo, SP: Paz e Terra, 1999.

. $O$ poder da identidade. São Paulo, SP: Paz e Terra, 1999.

. Fim de milênio. São Paulo, SP: Paz e Terra, 1999.

FRIEDMAN, M. Capitalismo e liberdade. São Paulo, SP: Arte Nova. 1977.

GRAMSCI, A. Os intelectuais e a organização da cultura. 9. ed. Rio de Janeiro, RJ: Civilização Brasileira. 1995. 
. Maquiavel, a política e o estado moderno. 8. ed. Rio de Janeiro, RJ: Civilização Brasileira, 1991.

HAYEK, F. $O$ caminho da servidão. 2. ed. Porto Alegre, Globo, 1977.

HARVEY, David. Condição pós-moderna. São Paulo, SP: Loyola, 1992.

LYOTHARD, J. F. O pós-moderno. Rio de Janeiro, RJ: José Olympio, 1985, p. 5.

MARX, KARL Contribuição a crítica da economia política. São Paulo, SP: Martins Fontes.1977.

. Teses sobre Feuerbach.(III), In: MARX, Karl; ENGELS, Friedrich. Textos. São Paulo, SP: Sociais, 1977. v. 3. p.118.

. O capital. São Paulo, SP: Nova Cultural. 1985, v. 3.

SAVIANI, D. Educação e questões da atualidade. São Paulo, SP: Cortez, 1991, p. 98.

. Pedagogia histórico-crítica: primeiras aproximações. 6. ed. Campinas: Autores Associados, 1997.

. A nova lei da educação. 3. ed. Campinas: Autores Associados, 1997.

SHAFF, Adam. Historia e verdade. São Paulo, SP: Martins Fontes, 1978.

Recebido em: 14 de novembro de 2005.

Aceito em: 19 de dezembro de 2005. 